\title{
Synthesis and Analyses of Thermoelectric Lead Telluride
}

\author{
Dmytro Freik ${ }^{1}$, Rasit Ahiska ${ }^{2}$, Igor Gorichok ${ }^{1}$, Lyubomyr Nykyruy ${ }^{1}$, Natalia Dykun ${ }^{1}$, Kivilcim Aktas $^{3}$, Selim \\ Acar $^{3}$ and Gunay Ahiska ${ }^{4}$ \\ 1. Physicochemical Institute, Vasyl Stefanyk Precarpathian National University, Ivano-Frankivsk 76018, Ukraine \\ 2. Electronic and Computer Engineering Department, Faculty of Technology, Gazi University, Ankara, Teknikokullar 06500, Turkey \\ 3. Faculty of Sciences, Physics Department, Gazi University, Ankara 06500, Turkey \\ 4. Ankara University, Science Faculty, Department of Physics, Ankara
}

Received: November 20, 2011 / Accepted: August 07, 2012 / Published: January 25, 2013.

\begin{abstract}
The influence of chemical composition effects, modes of synthesis, pressing on the structural states and electrical qualities of lead telluride has been investigated. The analyses indicated that thermoelectric parameters of the investigated materials depend on technological factors. The results revealed that conductivity is $n$-type in stoichiometric composition equilibrium and lead-excess states, while conductivity is p-type in tellurium-excess states. The maximum value of the Seebeck coefficient, which characterizes the thermoelectric materials, was obtained at $\mathrm{d}=0.8-1.0 \mathrm{~mm}$ for powder fractions and 0.75-1.0 $\mathrm{GPa}$ for pressed.
\end{abstract}

Key words: Lead telluride, synthesis, thermoelectric materials, Seebeck coefficient.

\section{Introduction}

Lead telluride has been mainly studied as thermoelectricity and thermoelectric materials due to various factors. The first of them is the search for alternative, environmentally clean and inexpensive sources of electricity. Thermoelectric science, thermoelectric material science and the thermoelectric industry have significant advantages and prospects in this field $[1,2]$. As regards to material science, to the fore come the issues of the search for new connective material with high thermoelectric qualities is of primary importance, which appears to be a complicated task; or the development of special technological processes with the purpose of their improvement in materials which are already well-known and well-established in practice [3]. The other aspect appears to be more straightforward [1-8].

Corresponding author: Lyubomyr Nykyruy, assitant professor, research fields: Semiconductor, electronic properties, condensed matter, semiconductor technology and thermoelectricity. E-mail: lyubomyr.nykyruy@gmail.com.
As regards to thermoelectric materials (TM), it should be noted that they are effective if their properties approximate to a "phonon glass" and "electronic crystals". This is determined by the fact that TM should have low values of thermal conductivity and high electrical conductivity. An excellent thermoelectric material exhibits a large dimensionless figure of merit, the so-called $\mathrm{ZT}$ value, defined by $\mathrm{Z}=$ $\mathrm{S}^{2} / \rho \mathrm{k}=\mathrm{S}^{2} \sigma / \mathrm{k}$ where $S$ is the Seebeck coefficient (thermal power), $\sigma$ is the electrical conductivity, $T$ is the absolute temperature, and $k$ is the thermal conductivity. The figure of merit $Z$ increases proportionally to the Seebeck coefficient squared, and a high Seebeck coefficient is very effective in increasing the value of $Z$. Much effort has been made in the past few years to improve ZT by employing nanostructures, which reduce the thermal conductivity of the lattice and increase the Seebeck coefficient. For thermoelectric devices, $\mathrm{Z}$ and $\mathrm{ZT}$ values approach 2.75 $\times 10^{-3} \mathrm{~K}^{-1}$ and 1 at $300 \mathrm{~K}$, respectively $[2,9,10]$.

The metals possess low Seebeck coefficient (S) and 
are substantial electronic components of the thermal conductivity $\mathrm{k}_{\mathrm{e}}$. The insulators, at high values of Seebeck coefficient and moderate electronic component of the thermal conductivity, are characterized by a negligible amount of electrical conductivity $(\sigma)$. Semiconductors exhibited the most attractive thermoelectric properties; high mobility $\left(10^{3} \mathrm{~cm}^{2} \cdot \mathrm{V}^{-1} \cdot \mathrm{s}^{-1}\right)$ and optimal values of carrier concentration $\left(10^{18} \mathrm{~cm}^{-3}\right)$, Seebeck coefficient (100-300 $\left.\mathrm{mV} \cdot \mathrm{K}^{-1}\right)$, electrical conductivity $\left(10^{3}-10^{5}\right.$ $\left.\mathrm{Ohm}^{-1} \mathrm{~cm}^{-1}\right)$, and the possibility of gradually changing the electrical and thermal properties with composition, temperature, etc. $[4,11]$.

When considered, only the electrical components, the thermoelectric power factor $\mathrm{PF}=\mathrm{S}^{2} \sigma\left(\mathrm{Wm}^{-1} \mathrm{~K}^{-2}\right)$ and the temperature coefficient of power $\mathrm{PTF}=\mathrm{TS}^{2} \sigma$ $\left(\mathrm{Wm}^{-1} \mathrm{~K}^{-2}\right)$ are determined. For the best thermoelectric materials $\left(\mathrm{Bi}_{2} \mathrm{Te}_{3}\right)$ these values are $0.004 \mathrm{Wm}^{-1} \mathrm{~K}^{-2}$ and $0.5 \mathrm{Wm}^{-1} \mathrm{~K}^{-2}$, respectively. $\mathrm{PF}$ is more suitable for application on materials which are used for energy generation because it determines the level of electrical power, which can be obtained with a thermocouple.

The materials with high values of the average mass $(\mathrm{Bi}, \mathrm{Pb}, \mathrm{Te}, \mathrm{Sb})$, are characterized by low lattice thermal conductivity $\left(\mathrm{K}_{\mathrm{p}}\right)$, large numbers of atoms per unit cell, layered structures with high coordinating numbers and weak bonds between layers. For these types of semiconductors, $\mathrm{Bi}_{2} \mathrm{Te}_{3}$ and $\mathrm{Sb}_{2} \mathrm{Te}_{3}$, which are effective at room temperature, are foremost. As well as the aforementioned, lead telluride $\mathrm{PbTe}$ is also an important semiconductor in the temperature range 300-700 K [1].

Lead telluride crystallizes in the NaCl-type structure with the lattice parameter $\mathrm{a}=6.452 \AA$, and the melting point at $1,190 \mathrm{~K}$. The nature of chemical binding is complex and presents a mixed ionic-covalent-metallic type. Lattice ionicity determines the significant (considering the order of magnitude) difference between the static $\varepsilon_{0}$ and the high-frequency dielectric penetrability $\varepsilon_{\infty}$. The existence of a bilateral homogeneity and deviation from the stoichiometric composition is typical for $\mathrm{PbTe}$. This causes high values of carrier concentration $10^{18}-10^{20} \mathrm{~cm}^{-3}$ and distinct conductivity. In this case, the excess of $\mathrm{Pb}$ determines the n-type, and the excess of Te the p-type conductivity, respectively. The width of the forbidden band gap is $0.32 \mathrm{eV}$ at $300 \mathrm{~K}$ with a multivalley characteristic of the energy spectrum. Thermoelectric material has low values of the lattice thermal conductivity $\left(\mathrm{k}_{1}=2.09 \times 10^{-2} \mathrm{WtK}^{-1} \mathrm{~cm}^{-1}\right)$, relatively high mobility $\left(\mu \approx 10^{3} \mathrm{~cm}^{2} \mathrm{~B}^{-1} \mathrm{~s}^{-1}\right.$ ), large value of ratio $\mu / \mathrm{k}$ that leads to a significant rise of thermoelectric figure of merit $\mathrm{Z}$ [4].

The isomorphic solid solutions with $\mathrm{PbSe}, \mathrm{SnTe}$ and other compounds exist on the basis of lead telluride. They lead to a significant decrease in the value of thermal conductivity with an increase in thermoelectric efficiency [5-8].

In recent years, the interest in lead telluride has been to increase its growth and to improve its thermoelectric properties [3]. In this paper, we focus on the production of lead telluride samples, and the improvement of its properties in its thermoelectric performance. Therefore, samples were grown for different technological elements of the synthesis. We measured thermoelectric properties of samples depending on $\Delta \mathrm{T}$, grain sizes and different pressed.

\section{Experiments}

The technological details of lead telluride synthesis are listed in Table 1. We have fabricated four different samples for examination of their electrical properties. One of them (ampoule I) is in stoichiometric composition equilibrium, the others with an excess of tellurium (ampoules II, IV) and lead (ampoule III). The synthesis was carried out in evacuated quartz ampoules, which were pre-washed with a mixture of nitric and hydrochloric acid $\left(\mathrm{HNO}_{3}: \mathrm{HCl}(1: 3)\right)$ for $2 \mathrm{~h}$. The ampoules were evacuated to a pressure of $2 \times 10^{4}$ $\mathrm{mmHg}$; tellurium and lead were filled respectively, sealed and kept for $0.5 \mathrm{~h}$. Then, the ampoules I and II were contained for $132 \mathrm{~h}$ and the ampoules III and IV 
for $1 \mathrm{~h}$ at a temperature of 1,290 K (Table 1). In the preheating process, ampoules I, II were annealed for 3 $\mathrm{h}$ and ampoules III, IV were annealed for 1-hour at 970 $\mathrm{K}$. The cooling of the synthesized material in the ampoule was carried out directly in open air (ampoules III and IV) or by the cyclical lowering of the oven temperature directly (ampoules I and II). The resulting material was ground in an agate mortar, and then, after being divided into fractions $0.0-0.6 \mathrm{~mm}, 0.6-0.8 \mathrm{~mm}$, 0.8-1.0 mm, was compressed under a pressure of 0.5-1 GPa, which resulted in the cylindrical-shape samples with $\mathrm{d}=5 \mathrm{~mm}$ and $1 \approx 10 \mathrm{~mm}$.

The phase composition of the obtained material was determined by an X-ray diffraction method on a DRON-3 facility, under chromium radiation, with the usage of powders from Bragg-Brentano geometry and over the range of scanning angles $20^{\circ} \leq 2 \theta \leq 110^{\circ}$. The $\mathrm{x}$-ray-phase analysis was performed by means of the full-profile Rietveld method and the software package, FulProf.

The magnitude of the thermo electromotive power was determined by means of standard procedures. The scheme of the experimental setup is shown in Fig. 1 [12]. With the help of heaters, $\mathrm{T}_{1}$ and $\mathrm{T}_{2}$ in the upper and lower surfaces of the sample temperature, respectively, temperatures were created and $T_{1}$ was found to be higher than $\mathrm{T}_{2}$.
The temperature of the surfaces was measured by thermocouples "Chromel-Alumel". The contacts were formed on the surfaces of the sample, and their potential differences were measured with a digital millivoltmeter (V7-16A). During the measurements, the $T_{2}$ temperature remained constant, but the $T_{1}$ temperature varied. The Seebeck coefficient $S$ was determined by the differences in temperature variations $(\Delta \mathrm{T})$ between the two surfaces of the sample.

\section{Results and Discussion}

\subsection{Optical Characteristics}

The results of XRD diffractogram are given in Fig. 2 for ampoule I. It should be noted that the phase composition of the synthesized material in the chosen technological conditions (Table 1) corresponds to the standard characteristics of the structure for the pure compound of lead telluride (Fig. 2). Diffractional lines of the individual components (Lead, Tellurium) or their oxides were not found on the diffraction patterns. The unfiltered complementary peaks (curves 1 and 2) are connected with $\mathrm{K}_{\alpha_{2}}^{\omega}$ and $\mathrm{K}_{\beta}^{\omega}$ by means of the characteristic radiation of chromium with respect to the standard lines of the crystalline compound $\mathrm{PbTe}$ (curve 3).

The micrographs of the thermoelectric $\mathrm{PbTe}$ are

Table 1 Technological details of the synthesis of thermoelectric PbTe.

\begin{tabular}{|c|c|c|c|c|}
\hline \multirow{2}{*}{ Importance of technological factors } & \multicolumn{4}{|c|}{ Ampoules } \\
\hline & $\mathrm{I}$ & II & III & IV \\
\hline Composition, wt. in \% & $\begin{array}{l}\mathrm{m}_{\mathrm{Pb}}=61.887 \\
\mathrm{~m}_{\mathrm{Te}}=38.113 \\
\text { Stoichiometric } \\
\text { composition } \\
\text { equilibrium }\end{array}$ & $\begin{array}{l}\mathrm{m}_{\mathrm{Pb}}=61.837 \\
\mathrm{~m}_{\mathrm{Te}}=38.163 \\
\text { Tellurium-excess }\end{array}$ & $\begin{array}{l}\mathrm{m}_{\mathrm{Pb}}=61.933 \\
\mathrm{~m}_{\mathrm{Te}}=38.067 \\
\text { Lead-excess }\end{array}$ & $\begin{array}{l}\mathrm{m}_{\mathrm{Pb}}=61.850 \\
\mathrm{~m}_{\mathrm{Te}}=38.150 \\
\text { Tellurium-excess }\end{array}$ \\
\hline Preheating temperature $T_{p}(K)$ & 970 & 970 & 970 & 970 \\
\hline Preheating time $t_{p}(h)$. & 3 & 3 & 1 & 1 \\
\hline Synthesis temperature $\mathrm{T}_{\mathrm{s}}(\mathrm{K})$ & 1,290 & 1,290 & 1,290 & 1,290 \\
\hline Synthesis time $t_{s}(h)$. & 132 & 132 & 1 & 1 \\
\hline Heating rate $V_{H}(K / h)$. & 100 & 100 & 1,000 & 1,000 \\
\hline Cooling rate $\mathrm{V}_{\mathrm{c}}(\mathrm{K} / \mathrm{h})$. & $\begin{array}{l}\text { Cooling in } \\
\text { the furnace, } \\
100\end{array}$ & $\begin{array}{l}\text { Cooling in } \\
\text { the furnace, } \\
100\end{array}$ & $\begin{array}{l}\text { Cooling in } \\
\text { the air, } \\
1,000\end{array}$ & $\begin{array}{l}\text { Cooling in } \\
\text { the air, } \\
1,000\end{array}$ \\
\hline Conductivity type & $\mathrm{n}$ & $\mathrm{p}$ & $\mathrm{n}$ & $\mathrm{p}$ \\
\hline Seebeck coefficient $\alpha(\mathrm{mV} / \mathrm{K})$ (at $570 \mathrm{~K})$ & -123 & 303 & -200 & 254 \\
\hline
\end{tabular}






Fig. 1 The scheme for the Seebeck coefficient measurement. (1) sample, (2) heater, (3) thermocouple, (4) Copper rod, (5) tripod [12].

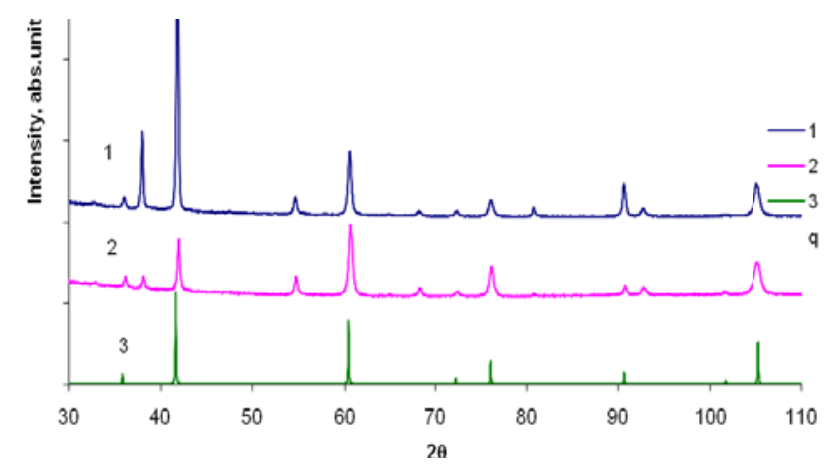

Fig. 2 Comparative diffractograms of the synthesized powder (1), pressed bale (2), lead telluride with rated data (3).

presented in Fig. 3. It is clear that the growth of microcrystals is sharply directed to dendritic, which is observed on the cleavage of the synthesized and cooled ingot (Fig. 3a). Dendritic growth begins, most probably, by cooling the ampoule from its walls, which is natural, and is then directed toward the center of the ingot. The orientational nature of the microcrystals is not destroyed even during the crushing of the ingot. This fact is indicated by the X-ray diffraction study, in particular (Fig. 2, curve 1). In the pressed tablets, orientational directivity of the crystallites is absent, as demonstrated by the studies on surface morphology (Fig. 3b) and X-ray data (Fig. 2, curve 2). In particular, the intensity of the line of the diffractional reflection (200) from the synthesized and milled material (Fig. 2, curve 1) is much higher than the one for the categorized material (Fig. 2, curve 3). Even for the pressed sample, the intensity of that same peak (Fig. 2, curve 2) is much smaller than the rated intensity (Fig. 2, curve 3). The latter is due to the fact that the crystal growth of PbTe in the synthesis has an explicit oriented structure in the direction of (100), which is partially preserved, even when the crystals are crushing. This is the reason for the observed significant increase in the intensity of the diffractional reflection (200) on the diffractograms (Fig. 2 , curve 1). The powder pressing completely destroys the orientational directivity of individual crystallites, which is reflected in the decrease in the intensity of this reflection (Fig. 2, curve 2).

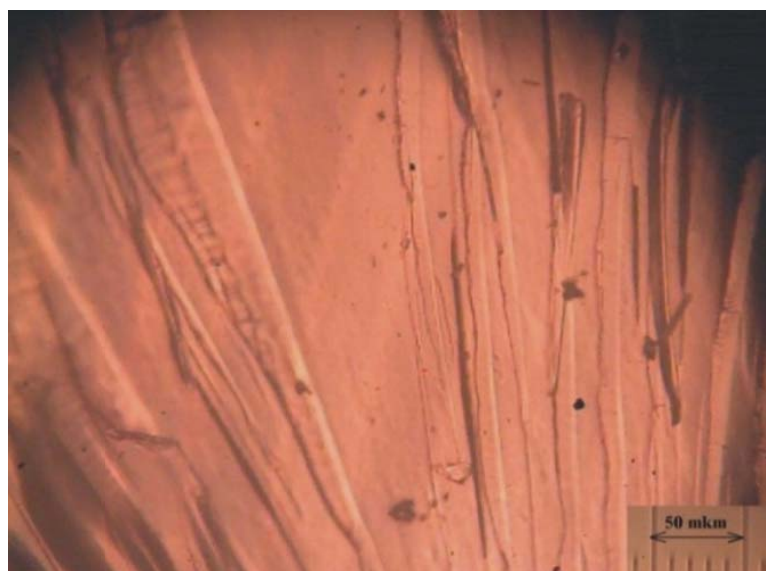

(a)

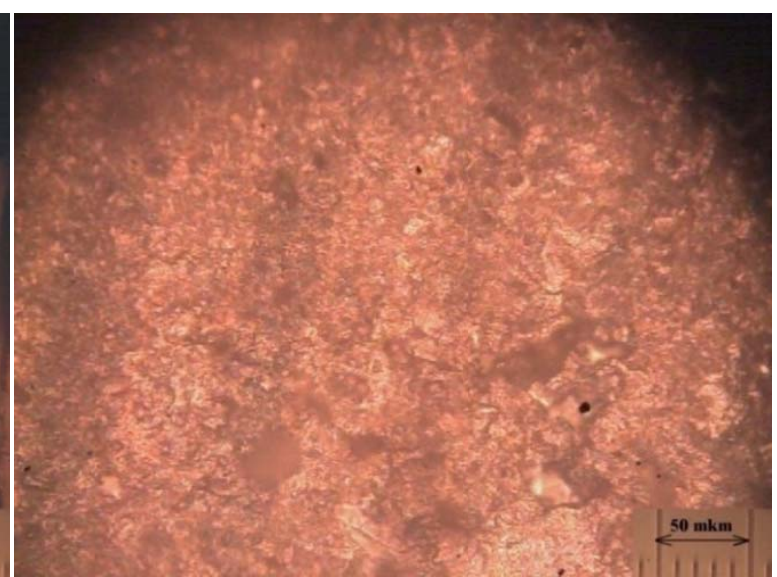

(b)

Fig. 3 The micrograph of the cleavage in the synthesized ingot (a) and pressed sample (b) of the thermoelectric PbTe. 


\subsection{Electrical Characteristics}

The electrical parameters of PbTe are given in Table 1. The materials which are synthesized from the stoichiometric composition (ampoule I) and lead-excess (ampoule III) have the electronic conductivity, while the tellurium-excess materials have the hole conductivity. The absolute value of Seebeck coefficient for $\mathrm{p}$-PbTe is significantly higher than (2-2.5 times) n-PbTe, also the stoichiometric composition is higher than (1.2-1.5 times) the lead-excess material at $570 \mathrm{~K}$. The differences in absolute values of Seebeck coefficient for $\mathrm{n}-\mathrm{PbTe}$ and $\mathrm{p}$-PbTe are determined by the peculiarities of the band structure and the transfer nature of the carriers (electrons or holes), as well as by their effective mass.

Temperature depending on the Seebeck coefficient for four samples, which were synthesized under different conditions, is plotted in Fig. 4. Fig. 5 presents the $\Delta \mathrm{T}$ depending Seebeck coefficient in ampoule II for different compaction pressures. For the fractions with different sizes, the $\Delta \mathrm{T}$ depending Seebeck coefficient in ampoule I, as shown in Fig. 6. Considering the figures for the samples, several facts can be observed. The magnitude of the thermoelectric power of $U$ with the increase in temperature differences $\Delta \mathrm{T}$ between the hot and cold ends of the samples for all cases under research, is changed by technological factors of the synthesis, and the magnitude of the fractions of grinding powders, and values of compaction pressure, also is increased (Fig. 6). The biggest absolute change in the $\Delta U$ is typical for p-type samples in the investigated temperature range.

The relationship of the Seeback coefficient $(\alpha)$ with $\Delta \mathrm{T}$ is determined by the chemical composition of the samples. Thus, in the samples obtained by the synthesis of components of the stoichiometric composition (ampoule I), Seebeck coefficient proportionally changes with increasing $\Delta \mathrm{T}$ for all powder fractions (Fig. 4, curve 1 and Fig. 6). In cases of the deviation from the stoichiometric composition, both lead-excess

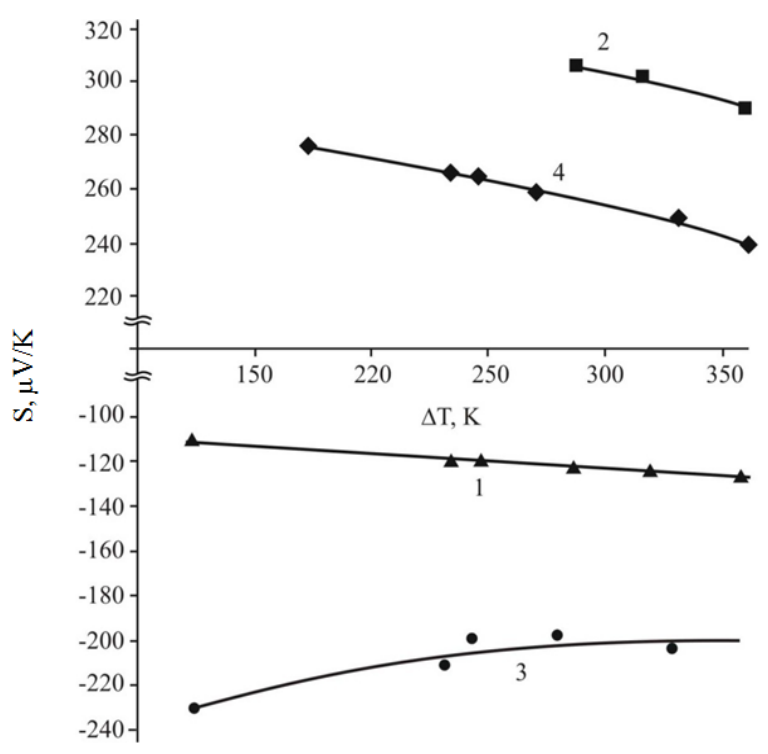

Fig. 4 The dependence of Seebeck coefficient (S) on the temperature difference $(\Delta \mathrm{T})$ of PbTe, obtained for various technological factors: (1) ampoule I, (2) ampoule II, (3) ampoule III, (4) ampoule IV.

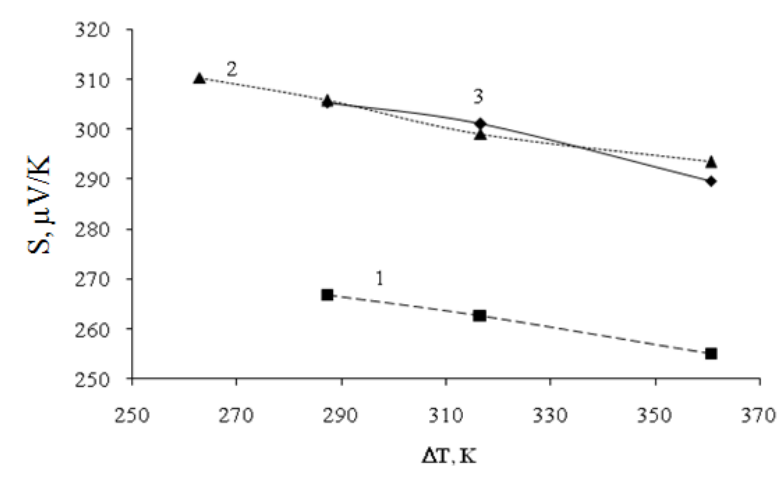

Fig. 5 In ampoule II, Seebeck coefficient versus the temperature difference $(\Delta \mathrm{T})$ for different compaction pressures of PbTe (1) 0.5 GPa, (2) 0.75 GPa, (3) 1.0 GPa.

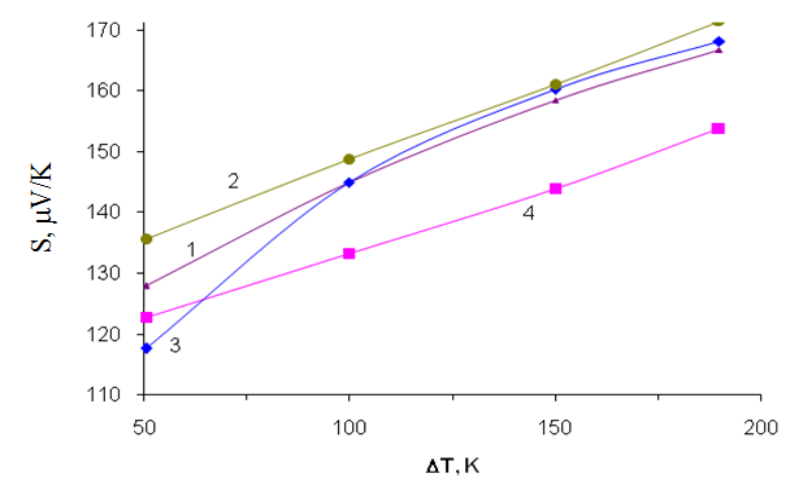

Fig. 6 In ampoule I, Seebeck coefficient versus the temperature difference $(\Delta \mathrm{T})$ of $\mathrm{PbTe}$, the fractions with different size d, mm: (1) monolith, (2) 0.8-1.0, (3) 0.6-0.8, (4) 0.0-0.6. 
and tellurium-excess, properties appear which possess opposite characteristics (Fig. 4, curves 2, 3, 4, Fig. 5). Such differences can be explained either by activational processes or by possible segregation of redundant components which are not detected by an $\mathrm{X}$-ray method and accumulated at the grain boundaries. The temperature raise leads to an increase in conductivity, which is the cause of the decrease in the $\mathrm{S}$ magnitude.

The value of Seebeck coefficient is affected significantly by the magnitude of powder fractions (Fig. 6) and compaction pressure (Fig. 5). It should be noted that the maximum value of $\mathrm{S}_{\max }$ is obtained from the powder fractions 0.8-1.0 $\mathrm{mm}$ in size (Fig. 6, Curve 2) at pressures 0.75-1.0 GPa (Fig. 5, curve 2, 3). Small fractions (i.e. 0.0-0.6 mm) (Fig. 6, curve 4) and low pressures (i.e., $0.5 \mathrm{GPa}$ ) (Fig. 5, curve 1) correspond to the lowest values of the Seebeck coefficient. The decrease in the number of material particles and material porosity bring about the decrease of the Seebeck coefficient. Subsequently, this evidence reflects that the former is without doubt, more effective than the latter.

\subsection{Crystal-Chemical Analysis of the Defect Subsystem}

The remarkable features, depending on the composition of thermoelectric parameters, are related to the nature of the defect subsystem of crystal structure, the type of point defects and their charge state. The analysis of the defect subsystem state is more than suitable to perform by means of crystalochemical formalism.

The method of the crystalquasichemical analysis is based on the superposition of the crystal-chemical clusters of basic and alloying compounds, which are formed on the basis of anti-structure of the main matrix [13]. The antistructure of lead telluride is presented by galena $\mathrm{V}_{\mathrm{Pb}}^{\prime \prime} \mathrm{V}_{\mathrm{Te}}^{\bullet \bullet}$, where $\mathrm{V}_{\mathrm{Pb}}^{\prime \prime}$ and $\mathrm{V}_{\mathrm{Te}}^{\bullet \bullet}$ doubly charged negative lead vacancy and positive telluride vacancy, “"” and "•" are negative and positive charges, respectively.
Crystalquasichemical cluster of n-PbTe (an excess of lead within the area of homogeneity), accounting for the disproportionation of the vacancies in the cationic sublattice of $\mathrm{Pb}$ has the form:

$$
\begin{aligned}
& \mathrm{V}_{\mathrm{Pb}}^{\prime \prime} \mathrm{V}_{\mathrm{Te}}^{\bullet \bullet}+\mathrm{Pb}^{0} \rightarrow \\
& {\left[\mathrm{Pb}_{1-\sigma}^{\times} \mathrm{V}_{\sigma(1-\delta)}^{\prime \prime} \mathrm{V}_{\sigma \delta}^{\prime}\right]_{\mathrm{Pb}} \mathrm{V}_{\mathrm{Te}}^{\bullet \bullet}\left(\mathrm{Pb}_{\sigma}^{\bullet \bullet}\right)_{\mathrm{i}}+(2+\sigma \delta) \mathrm{e}^{\prime},} \\
& \text { and crystalquasichemical formula of n-PbTe looks } \\
& \qquad(1-\alpha)\left\{\mathrm{Pb}_{\mathrm{Pb}}^{*} \mathrm{Te}_{\mathrm{Te}}^{*}\right\} \\
& +\alpha\left\{\left[\mathrm{Pb}_{1-\sigma}^{*} \mathrm{~V}_{\sigma(1-\delta)}^{\prime \prime} \mathrm{V}_{\sigma \delta}^{\prime}\right]_{\mathrm{Pb}} \mathrm{V}_{\mathrm{Te}}^{\bullet \bullet}\left(\mathrm{Pb}_{\sigma}^{\bullet \bullet}\right)_{\mathrm{i}}+(2+\sigma \delta) \mathrm{e}^{\prime}\right\} \\
& \rightarrow\left[\mathrm{Pb}_{1-\alpha \sigma}^{*} \mathrm{~V}_{\alpha \sigma(1-\delta)}^{\prime \prime} \mathrm{V}_{\alpha \sigma \delta}^{\prime}\right]_{\mathrm{Pb}}\left[\mathrm{Te}_{1-\alpha}^{*} \mathrm{~V}_{\alpha}^{\bullet \bullet}\right]_{\mathrm{Te}}\left(\mathrm{Pb}_{\alpha \sigma}^{\bullet \bullet}\right)_{\mathrm{i}}+ \\
& (2 \alpha+\alpha \sigma \delta) \mathrm{e}^{\prime} . \\
& \text { Here } \\
& \quad\left[\mathrm{V}_{\alpha \sigma}^{\prime \prime}\right]_{\mathrm{Pb}} \rightarrow\left[\mathrm{V}_{\alpha \sigma(1-\delta)}^{\prime \prime}\right]_{\mathrm{Pb}}+\left[\mathrm{V}_{\alpha \sigma \delta}^{\prime}\right]_{\mathrm{Pb}}+\alpha \sigma \delta \mathrm{e}^{\prime}
\end{aligned}
$$

Similarly, the crystalquasichemical representation of non-stoichiometric p-PbTe (an excess of tellurium within the homogeneity area) is described as

$$
\begin{gathered}
\mathrm{V}_{\mathrm{Pb}}^{\prime \prime} \mathrm{V}_{\mathrm{Te}}^{\bullet \bullet}+\mathrm{Te}^{0} \rightarrow \\
{\left[\mathrm{V}_{1-\delta}^{\prime \prime} \mathrm{V}_{\delta}^{\prime}\right]_{\mathrm{Pb}}\left[\mathrm{Te}_{1-\gamma}^{*} \mathrm{~V}_{\gamma}^{\cdot \bullet}\right]_{\mathrm{Te}}\left(\mathrm{Te}_{\gamma}^{*}\right)_{\mathrm{i}}+(2-2 \gamma-\delta) \mathrm{h}^{\bullet},} \\
(1-\beta)\left\{\mathrm{Pb}_{\mathrm{Pb}}^{*} \mathrm{Te}_{\mathrm{Te}}^{*}\right\} \\
+\beta\left\{\left[\mathrm{V}_{1-\delta}^{\prime \prime} \mathrm{V}_{\delta}^{\prime}\right]_{\mathrm{Pb}}\left[\mathrm{Te}_{1-\gamma}^{*} \mathrm{~V}_{\gamma}^{\bullet \bullet}\right]_{\mathrm{Te}}\left(\mathrm{Te}_{\gamma}^{*}\right)_{\mathrm{i}}\right. \\
\left.+(2-2 \gamma-\delta) \mathrm{h}^{\bullet}\right\} \rightarrow, \\
\rightarrow\left[\mathrm{Pb}_{1-\beta}^{*} \mathrm{~V}_{\beta(1-\delta)}^{\prime \prime} \mathrm{V}_{\beta \delta}^{\prime}\right]_{\mathrm{Pb}}\left[\mathrm{Te}_{1-\beta \gamma}^{*} \mathrm{~V}_{\beta \gamma}^{\bullet \bullet}\right]_{\mathrm{Te}}\left(\mathrm{Te}_{\beta \gamma}^{*}\right)_{\mathrm{i}} \\
+\beta(2-2 \gamma-\delta) \mathrm{h}^{\bullet}
\end{gathered}
$$

Here $\left[\mathrm{V}_{\beta}^{\prime \prime}\right]_{\mathrm{Pb}} \rightarrow\left[\mathrm{V}_{\beta(1-\delta)}^{\prime \prime}\right]_{\mathrm{Pb}}+\left[\mathrm{V}_{\beta \delta}^{\prime}\right]_{\mathrm{Pb}}+\beta \delta \mathrm{e}^{\prime} ; \alpha$ ( $\beta$ ) is the value of the initial deviation from the stoichiometric composition towards $\mathrm{Pb}(\mathrm{Te}) ; \delta$ is the coefficient of disproportionation in the charge state of lead vacancies; $\sigma(\gamma)$ is the fraction of interstitial atoms $\mathrm{Pb}(\mathrm{Te})$; $\mathrm{e}^{\prime}$, electrons, $\mathrm{h}^{\bullet}$, holes, $\mathrm{Pb}_{\mathrm{Pb}}^{*} \mathrm{Te}_{\mathrm{Te}}^{*}$, lead and tellurium in the sites of the crystal lattice, "**", an effective neutral charge, "0”, zero charge.

The obtained crystalquasichemical Eqs. (1) and (2) allow for calculation of the concentration of point defects in the cationic and anionic sublattices and free charge carriers $(n, p)$, depending on the composition of both $\mathrm{n}$-PbTe and $\mathrm{p}$-PbTe.

In particular, the electroneutrality equation, according to (1) is written as:

$$
\begin{gathered}
n+q_{V_{P b}^{\prime \prime}}\left[\mathrm{V}_{\mathrm{Pb}}^{\prime \prime}\right]+q_{V_{P b}}\left[\mathrm{~V}_{\mathrm{Pb}}^{\prime}\right]=q_{V_{T e}^{\bullet \bullet}}\left[\mathrm{V}_{\mathrm{Te}}^{\bullet \bullet}\right] \\
+q_{P b_{i}^{* \bullet}}\left[\mathrm{Pb}_{\mathrm{i}}^{\bullet \bullet}\right]
\end{gathered}
$$


$A \alpha \sigma \delta,\left[V_{T e}^{\bullet \bullet}\right]=A \alpha,\left[\mathrm{Pb}_{\dot{\mathrm{i}}}^{\bullet \bullet}\right]=A \alpha \sigma, q_{V_{P b}^{\prime}}=1, q_{V_{P b}^{\prime \prime}}=$ $q_{V_{T e} \cdot}=q_{P b_{i}}=2$.

Then, the Hall concentration is given by:

$$
\mathrm{n}_{\mathrm{H}}=A(2 \alpha+\alpha \sigma \delta)
$$

For the superstoichiometry of Te Eq. (2) by analogy

$$
\begin{aligned}
q_{V_{P b}^{\prime \prime}}\left[\mathrm{V}_{\mathrm{Pb}}^{\prime \prime}\right]+q_{V_{P b}^{\prime}}\left[\mathrm{V}_{\mathrm{Pb}}^{\prime}\right]=p+ \\
\mathrm{q}_{\mathrm{V}_{\mathrm{Te}}}\left[\mathrm{V}_{\mathrm{Te}}^{\bullet \bullet}\right] \\
\mathrm{n}_{\mathrm{H}}=\mathrm{A} \beta(2-2 \gamma-\delta)
\end{aligned}
$$

Here, $p=A \beta(2-2 \gamma-\delta)$; $\left[\mathrm{V}_{\mathrm{Pb}}^{\prime \prime}\right]=A \beta(1-\delta)$; $\left[\mathrm{V}_{\mathrm{Pb}}^{\prime}\right]=A \beta \delta ; \quad\left[\mathrm{V}_{\mathrm{Te}}^{\bullet \bullet}\right]=A \beta \gamma, \quad \mathrm{q}_{\mathrm{V}_{\mathrm{Pb}}^{\prime}}^{\prime}=1 ; \quad \mathrm{q}_{\mathrm{Vb}}^{\prime \prime}=$ $\mathrm{q}_{\mathrm{V}_{\mathrm{Te}}^{*}}=2 ; \quad A=\frac{2 \mathrm{Z}}{\mathrm{a}^{3}}$; where $Z$ is the number of structural units per unit cell $(Z=4)$, a, is a lattice parameter.

The carrier concentration is calculated using the Eqs. (4) and (6) and are shown in Fig. 7 and 8. Fig. 7 shows the dependence of the Hall carrier concentration on the lead content within the homogeneity area of $\mathrm{PbTe}$ compounds. Fig. 8 shows the dependence of the Hall concentration $\left(1-n_{H}\right)$, the concentration of point defects $\left(\mathrm{N}_{\mathrm{i}}\right)$ on the deviation from the stoichiometric composition for $\mathrm{n}-\mathrm{PbTe}$ (a) and p-PbTe (b).

Thus, the electronic conductivity of lead telluride is connected with vacancies in the anionic $\left[\mathrm{V}_{\mathrm{Te}}^{\bullet}\right]$ (Fig. 8, a, curve 2), while the hole conductivity is connected with in the cationic (Fig. 8b, curves 3 and 4) sublattices of the crystal structure of lead telluride, respectively.

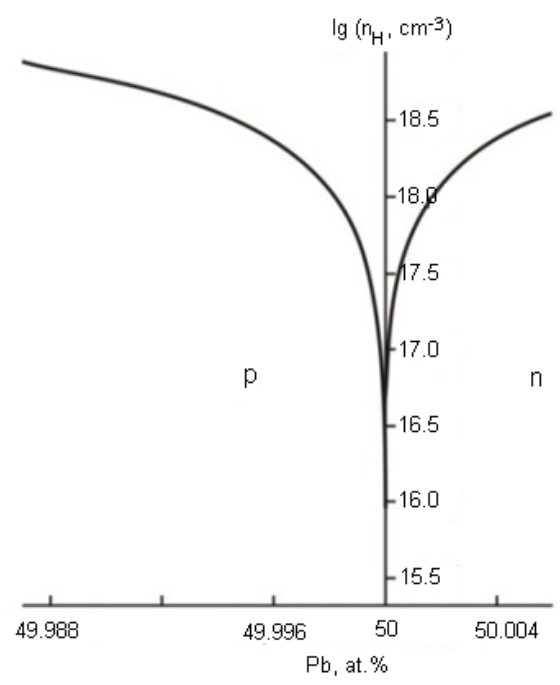

Fig. 7 The dependence of the Hall carrier concentration on lead content within the homogeneity area of PbTe compounds.

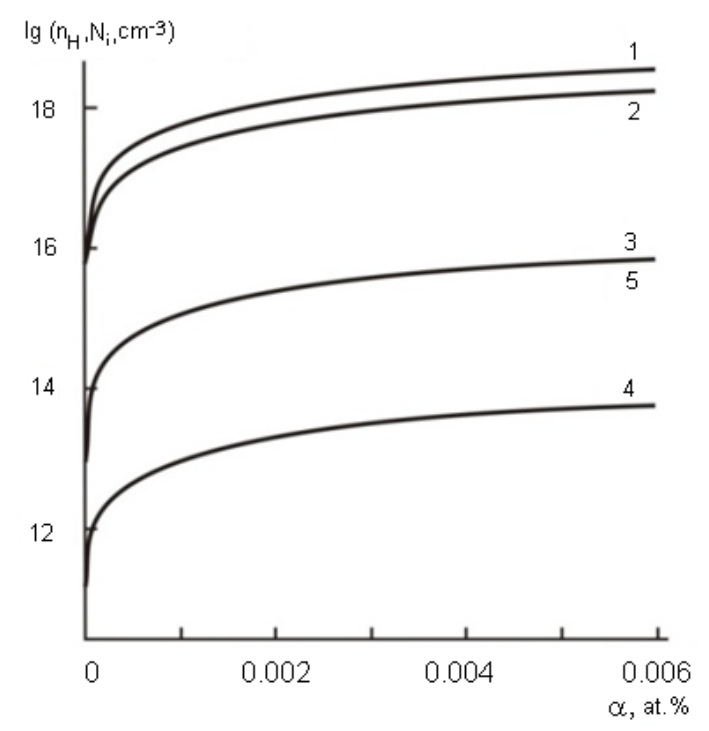

(a)

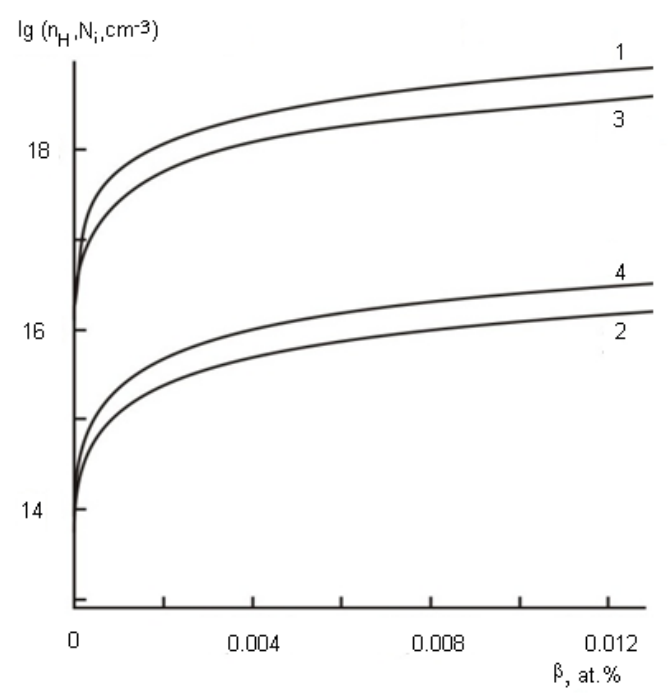

(b)

Fig. 8 The dependence of the Hall concentration $\left(1-n_{H}\right)$, the concentration of point defects $\left(\mathrm{N}_{\mathrm{i}}\right)$ on the deviation from the stoichiometric composition for n-PbTe (a) and p-PbTe (b): $2-\left[\mathbf{V}_{\mathrm{Te}}^{2+}\right], 3-\left[\mathbf{V}_{\mathbf{P b}}^{2-}\right], 4-\left[\mathbf{V}_{\mathbf{P b}}^{-}\right], 5-\left[\mathbf{P b}_{\mathbf{i}}^{2+}\right]$.

\section{Conclusions}

This study was the synthesis of the thermoelectric lead telluride performed under different technological conditions and analyzes the phase composition, and the structure and electrical properties of diverse chemical composition. It was concluded that stoichiometric composition equilibrium and lead-excess sample have n-type conductivity, while tellurium-excess samples 
have p-type conductivity. The maximum value of Seebeck coefficient was obtained at $\mathrm{d}=0.8-1.0 \mathrm{~mm}$ for powder fractions and 0.75-1.0 $\mathrm{GPa}$ for pressed. The obtained values of Seebeck coefficient of thermoelectric $\mathrm{PbTe}$-type are significantly greater than other concerning electronic material. This article also represents the models of the thermoelectric defect subsystem for $\mathrm{n}-\mathrm{PbTe}$ and $\mathrm{p}-\mathrm{PbTe}$ within the scope of crystalochemical formalism.

\section{Acknowledgment}

Paper support by Turkish-Ukraine project No:109T642 (Turkish State Registration Number) and No: M/86-2010 (Ukraine State Registration Number), «New semiconductor materials on the base of lead telluride for thermoelectric energy transformers».

\section{References}

[1] L.I. Anatychuk, Thermocouples and Thermoelectric Devices, Naukova Dumka, 1979, p. 766.

[2] K. Kishimoto, T. Koyanagi, Preparation of sintered degenerate n-type $\mathrm{PbTe}$ with a small grain size and its thermoelectric properties, J. Appl. Phys. 92 (2002) 2544-2549.

[3] Y.P. Szabo, Chalcogenide thermoelecouple technology: The increase in the thermoelectric efficiency, Thermoelectricity 4 (2000) 49-57.

[4] V.M. Shperun, D.M. Freik, R.I. Zapuhlyak, The Thermoelectricity of Lead Telluride and its Analogues,
Ivano-Frankovsk, Plai, 2000, p. 250.

[5] P. Zhu, Y. Imai, Y. Isoda, Y. Shinohara, X. Jia, G. Zou, Enhanced thermoelectric properties of PbTe alloyed with $\mathrm{Sb}_{2} \mathrm{Te}_{3}$, J. Phys.: Condens. Matter 17 (2005) 7319-7326.

[6] G.T. Alekseeva, E.A. Gurieva, P.P. Konstantinov, L.V. Prokofeva, Y.I. Ravich, Nature of hole localization centers in sodium-doped lead chalcogenides, Semiconductors 31 (1997) 446-448.

[7] G.T. Alekseeva, M.V. Vedernikov, E.A. Gurieva, L.V. Prokofeva, Y.I. Ravich, Hole concentration and thermoelectric figure of merit for $\mathrm{Pb}_{1-{ }_{\mathrm{x}}} \mathrm{Sn}_{\mathrm{x}} \mathrm{Te}$ :Te solid solutions, Semiconductors 34 (2000) 897-901.

[8] E.A. Gurieva, P.P. Konstantinov, L.V. Prokofeva, Y.I. Ravich, M.I. Fedorov, Thermoelectric figure of merit in solid solutions with phonon scattering by off-center impurities, Semiconductors 37 (2003) 276-282.

[9] A. Ishida, T. Yamada, D. Cao, Y. Inoue, M. Veis, T. Kita, Seebeck effect in $\mathrm{PbTe}$ films and EuTe/PbTe superlattices, J. Appl. Phys. 106 (2009) 023718.

[10] I. Y. Erdoğan, U. Demir, Synthesis and characterization of $\mathrm{Sb}_{2} \mathrm{Te}_{3}$ nanofilms via electrochemical co-deposition method, J. Electroanal. Chem. 633 (2009) 253-258.

[11] O. Yamashita, Resultant Seebeck coefficient formulated by combining the Thomson effect with the intrinsic Seebeck coefficient of a thermoelectric element, Energy Convers. Manage. 50 (2009) 2394-2399.

[12] C. Kriskov, M. Kiselyuk, S. Levitsky, N. Melnyk, Influence of impurity on a type of conductivity of connections on a basis PbTe, Vestnik of Lviv University, Physical series 39 (2006) 82-87.

[13] S.S. Lisnyak, Crystal-quasi-chemical model in chemistry of solids, Inorg. Mater. 28 (1992) 1913-1917. 